\title{
Development of a Photodynamic Diagnosis Method for Oral Squamous Cell Carcinoma Using 5-Aminolevulinic Acid and a Luminescence Plate Reader
}

\author{
Hiroko Omori ${ }^{1}$, Chiaki Komine ${ }^{2}$ \\ ${ }^{1}$ Laboratory Medicine for Dentistry, Graduate School of Dentistry at Matsudo, Nihon University, Matsudo, Japan \\ ${ }^{2}$ Department of Laboratory Medicine and Dentistry for the Compromised Patient, Nihon University, Matsudo, Japan \\ Email: mahi18004@g.nihon-u.ac.jp
}

How to cite this paper: Omori, H. and Komine, C. (2021) Development of a Photodynamic Diagnosis Method for Oral Squamous Cell Carcinoma Using 5-Aminolevulinic Acid and a Luminescence Plate Reader. Open Journal of Stomatology, 11, 325-340. https://doi.org/10.4236/ojst.2021.119029

Received: July 29, 2021

Accepted: September 4, 2021

Published: September 7, 2021

Copyright $\odot 2021$ by author(s) and Scientific Research Publishing Inc. This work is licensed under the Creative Commons Attribution International License (CC BY 4.0).

http://creativecommons.org/licenses/by/4.0/

(c) (i) Open Access

\begin{abstract}
Purpose: To establish a simple and accurate photodynamic diagnosis (PDD) method for oral squamous cell carcinoma (OSCC). Methods: OSCC cell lines HSC-2, HSC-3, HSC-4, and Sa3, and normal human oral keratinocytes (HOK) were used. First, we examined the amount of cells needed to detect differences in fluorescence intensities for PDD. OSCC cell lines were adjusted to concentrations of $1 \times 10^{4}\left(10^{4}\right), 1 \times 10^{5}\left(10^{5}\right)$, and $1 \times 10^{6}\left(10^{6}\right)$ cells $/ \mathrm{ml}$. The experimental groups comprised a group with 5-aminolevulinic acid (5-ALA $(+)$ ), and a group without 5-ALA (5-ALA (-)). For each OSCC cell line, 100 $\mu \mathrm{l}$ of each concentration of cells of the 5-ALA groups was seeded onto fluorescence plates, and fluorescence intensity was measured at 60-min intervals for $240 \mathrm{~min}$. Results are expressed as the ratio of fluorescence intensity in 5-ALA (+) to 5-ALA (-). As cells at the concentration of $10^{6}$ cells $/ \mathrm{ml}$ provided the clearest results, fluorescence intensities of all cell lines were measured using this concentration at 20-min intervals for 700 min using the same methods. Results: The 5-ALA (+) to $(-)$ ratio increased in a cell concentration-dependent manner at $240 \mathrm{~min}$; the ratio was highest with $10^{6} \mathrm{cells} / \mathrm{ml}$ and lowest with $10^{4}$ cells $/ \mathrm{ml}$. With $10^{6}$ cells $/ \mathrm{ml}$ in the 5-ALA (+) group, fluorescence intensity increased in a metabolic time-dependent manner; the increase was highest in HSC-2 cells, followed by HSC-4 cells, HSC-3 cells, Sa3 cells, and HOK. Fluorescence intensity was significantly enhanced after 40 min in HSC-2, HSC-3, and HSC-4 cells, after $60 \mathrm{~min}$ in Sa3 cells, and after 100 min in HOK compared to the 5-ALA $(-)$ group $(P<0.05)$. Moreover, fluorescence intensity was significantly increased in OSCC cell lines compared to HOK after $40 \mathrm{~min}$. Conclusion: Early detection of OSCC is possible
\end{abstract}


by screening only microplate reader measurements of fluorescence intensity for PDD.

\section{Keywords}

Luminescence Plate Reader, 5-Aminolevulinic Acid (5-ALA), Photodynamic Diagnosis (PDD), Oral Squamous Cell Carcinoma (OSCC)

\section{Introduction}

Deaths from oral cancer have been on the rise for about 20 years in Japan [1]. This trend is expected to continue to increase with Japan's super-aging society. Approximately $90 \%$ of malignancies occurring in the oral cavity are squamous cell carcinomas [2]. Generally, surgical resection, chemotherapy, and radiation therapy are the treatments of choice for malignant tumors, and oral malignant tumors are no different. Therefore, advanced oral cancer can cause serious dysfunction and aesthetic problems after treatment. The quality of life of patients may become significantly impaired by these factors. For these reasons, early detection and early treatment of oral malignant tumors are extremely important.

From the viewpoint of early detection, there is a significant difference between oral malignant tumors and tumor in other parts of the body: The oral cavity can be viewed and reached directly due to its location, so it is possible to determine the local pathological condition by inspection or palpation; however, this is not possible for tumors arising in other areas. Furthermore, when compared to other areas of the body, it is relatively easy to collect specimens from the oral cavity for testing. Despite these huge advantages when compared to tumors in other parts of the body, the number of deaths from oral cancer is on the rise due to the lack of early detection in Japan. A reason for this is the differences in diagnostic techniques used among medical professionals [3] [4]. The basic methods used for the early detection of oral cancer are inspection, palpation, medical consultation, and imaging diagnosis. However, diagnostic evaluation depends on the experience and subjectivity of medical professionals, which can vary greatly between individuals.

Exfoliative cytology is used as an adjunctive diagnostic method to reduce the differences in evaluations among medical professionals. Exfoliative cytology has been reported to be useful in the dental field due to the simplicity of specimen collection, its low invasiveness, and the speed of obtaining test results [5]. However, due to the unique characteristics of the oral cavity, the evaluation of exfoliates from the oral cavity also varies depending on the experience of the cell screener, and the agreement rate with histology results varies greatly depending on the skill level of the individual performing the test. Therefore, it is extremely important to establish a visual quantitative diagnostic method for the early detection of oral cancer that can reduce the disparity in evaluations among medical professionals. 
Photodynamic diagnosis (PDD) has been applied for the diagnosis of malignancy and for the intraoperative diagnosis of cancers, and its ability to provide an objective evaluation via fluorescence intensity measurements for determining malignancy has been in the spotlight in the medical field.

PDD is a method of diagnosing tumors by detecting the fluorescence wavelength generated by a photosensitizer (PS) that has been administered into the body and taken up specifically by the tumor; the PS can be detected by irradiation with excitation light [6]. PDD has been investigated as a new technique in several tumors, and the clinical application of PDD using 5-aminolevulinic acid (5-ALA) as the PS has begun in the fields of gastroenterology, urology, and neurosurgery [7] [8] [9] [10]. 5-ALA is naturally present in small amounts in the human body, but it does not fluoresce by itself. When 5-ALA is administered intravitreally, it is taken up by tumors, and protoporphyrin IX (PpIX), a metabolite of 5-ALA, accumulates in the tumor cells (Figure 1). Under an excitation wavelength of $405 \mathrm{~nm}$, PpIX emits fluorescence at $630 \mathrm{~nm}$. PDD using fluorescence detection is effective in diagnosing the presence of tumors. However, in

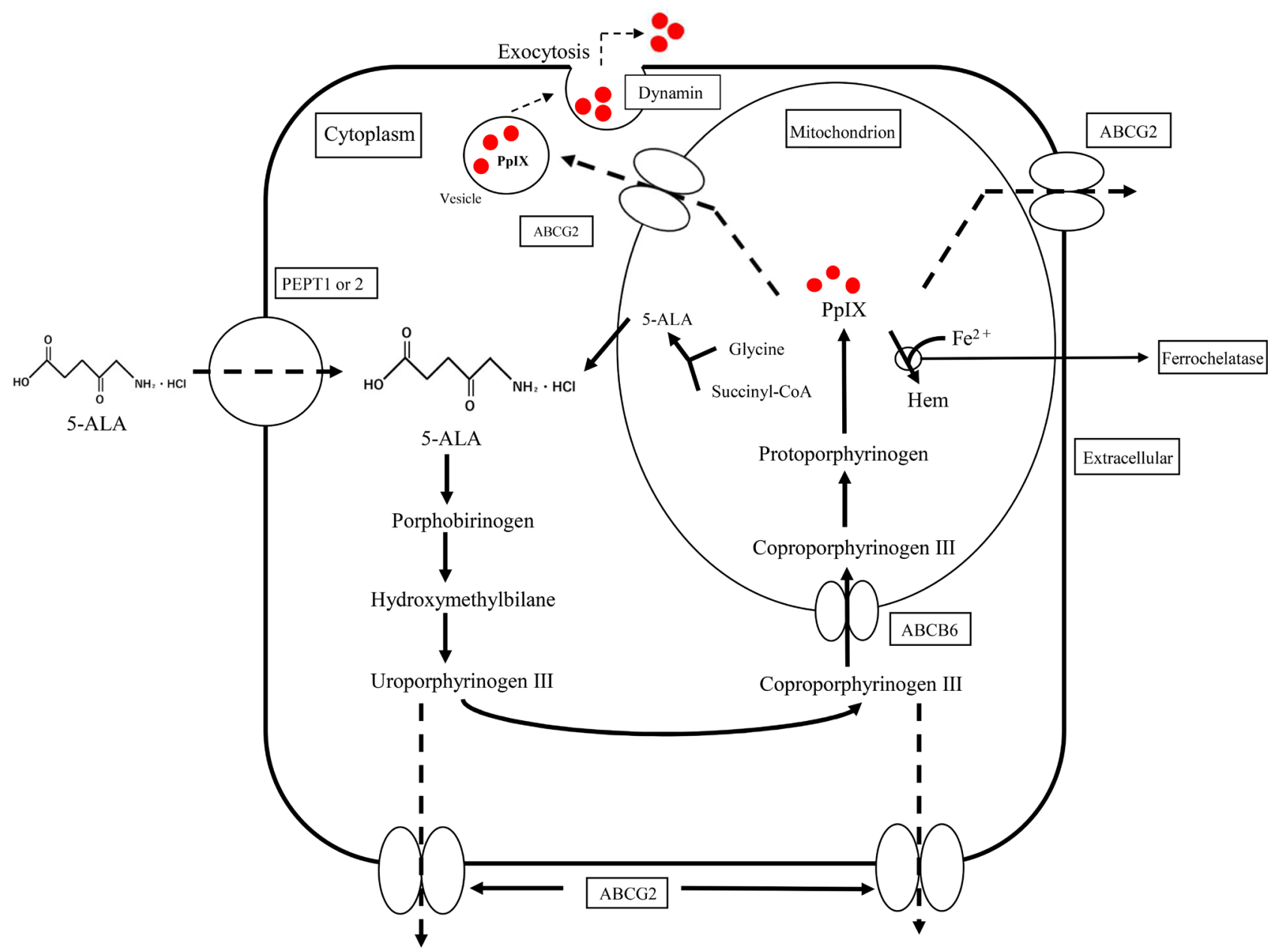

Figure 1. Metabolic pathway of exogenous 5-ALA administration. (Taken from the literature with some modifications [7] [9]). When 5-ALA is administered exogenously, it goes through various metabolic pathways in the cytoplasm, then becomes PpIX in the mitochondria. After that, $\mathrm{Fe}^{2+}$ forms a chelate complex with PpIX by the action of ferrochelatase to form heme. 
many malignant tumors, the lesions are located in areas that cannot be directly seen or reached, and the procedure is performed using an endoscope or similar device with limited vision and instrumentation.

Although 5-ALA is considered to be a substance with little phototoxicity or biotoxicity since it is naturally present in small amounts in the human body, and is only administered orally beforehand, there remains a possibility that 5-ALA may show some toxicity when administered into the body. Therefore, it is also important to ensure that its uptake is as efficient and harmless as possible.

This led us to focus on the use of exfoliative techniques as specimens from the oral region. We also thought that it would be useful to quantify the fluorescence intensity using a luminescence plate reader to eliminate subjectivity from individual diagnosticians, and to clarify the diagnostic criteria. PDD using a fluorescent plate reader on an exfoliated sample has not been previously reported in the Japanese or foreign literature. Therefore, we believe that the combined use of oral exfoliative cytology and PDD, and the development of quantitative diagnostic criteria for oral squamous cell carcinoma (OSCC) may enable the establishment of a safe and highly accurate chairside method for the diagnosis of oral cancer.

In this study, we performed PDD using 5-ALA on cultured human OSCC-derived cell lines and normal human oral keratinocytes (HOK) to develop a safe and accurate method for oral cancer diagnosis, and measured the fluorescence intensity of each cell line over time by irradiating them with excitation light and measuring the fluorescence intensity with a luminescence plate reader.

\section{Materials \& Methods}

1) Cell culture

In this study, we used the human OSCC cell lines HSC-2, HSC-3, HSC-4, and Sa3 (RIKEN, Tokyo, Japan), and normal human primary cultures of oral keratinocytes (HOK, ScienCell Research Laboratories, Carlsbad, CA, USA) as normal cell line.

Dulbecco's modified Eagle's medium (Sigma-Aldrich, St. Louis, MO, USA) containing $10 \%$ fetal bovine serum and $100 \mu \mathrm{g} / \mathrm{ml}$ penicillin-streptomycin (Gibco, St. Louis, MO, USA) was used for HSC-2, HSC-3, HSC-4, and Sa3, while oral keratinocyte medium (ScienCell Research Laboratories) containing $5 \mathrm{ml}$ of HOK growth supplement and $5 \mathrm{ml}$ of penicillin-streptomycin solution was used for $\mathrm{HOK}$. The cultures were maintained in an atmosphere of $5 \% \mathrm{CO}_{2}, 90 \% \mathrm{~N}_{2}$, and $5 \% \mathrm{O}_{2}$ at $37^{\circ} \mathrm{C}$. The culture media were changed every 3 days.

When the cultured cells had reached confluence, they were washed twice with phosphate-buffered saline, detached with $0.05 \%$ Trypsin- $0.53 \mathrm{mmol} / \mathrm{l}$ EDTA-4Na solution (Wako, Osaka, Japan) in an incubator, and collected by centrifugation. For experimental use, the cells of the $3^{\text {rd }}$ to $6^{\text {th }}$ passages were counted using a hemocytometer, then adjusted to the concentrations of $1 \times 10^{4}\left(10^{4}\right), 1 \times 10^{5}$ $\left(10^{5}\right)$, and $1 \times 10^{6}\left(10^{6}\right) \mathrm{cells} / \mathrm{ml}$, and an equal volume of trypan blue was added 
to $10 \mu \mathrm{l}$ of each cell suspension.

2) PS and fluorescence intensity measurement device

5-ALA (MW: 167.6, NeoPharma Japan, Tokyo, Japan) was used as the PS.

The 5-ALA was added to Dulbecco's modified Eagle's medium and adjusted to a final concentration of $2 \mathrm{mM}$ based on a previous report [11]. The fluorescence intensity was measured using a 1420 Multilable/Luminescence Counter ARVO MX (Perkin Elmer Japan Co., Ltd., Kanagawa, Japan). Cells were irradiated with a wavelength of $405 \mathrm{~nm}$, which is the excitation wavelength of the PpIX produced from 5-ALA, and the emitted fluorescence at a wavelength of $635 \mathrm{~nm}$ was measured as the fluorescence intensity.

3) Measurement of fluorescence intensity of each cell line by PDD

Each cell line was divided into two groups: A group treated with 5-ALA (5-ALA (+)) and a group without 5-ALA treatment as the control group (5-ALA $(-))$. For each cell line, $100 \mu \mathrm{l}$ of each of the tested concentrations of cells $\left(10^{4}\right.$, $10^{5}$, and $10^{6}$ cells $/ \mathrm{ml}$ ) was added to 96 -well luminescence plates, and the fluorescence intensity was measured at 60 -min intervals for $240 \mathrm{~min}$. Subsequently, the fluorescence intensity of cells at $10^{6} \mathrm{cells} / \mathrm{ml}$, which was the concentration that showed the strongest fluorescence intensity, was measured at 20-min intervals for 700 min under the same conditions $(n=7)$ (Figure 2).

4) Statistical analysis

The fluorescence intensities of the cell lines are shown as the mean \pm standard deviation (mean $\pm \mathrm{SD}$ ), and comparisons between the 5-ALA (-) group and the 5-ALA (+) group were performed using the Student's $t$-test.

For comparisons among cell lines, Scheffé's multiple comparison test was used after analysis of variance. $P$ values $<0.05$ were considered to be statistically significant. Analyses were performed using IBM SPSS Statistics ver. 22 (IBM, Tokyo, Japan).

\section{Results}

The fluorescence intensities obtained at $10^{4}$ to $10^{6} \mathrm{cells} / \mathrm{ml}$ for each cell line are shown as the ratio between the 5-ALA (+) group and the 5-ALA (-) group (Figures 3(a)-(d)).

In all cell lines, the 5-ALA (+)/5-ALA (-) ratio increased in a cell concentration-dependent manner: It was highest at the concentration of $10^{6}$, and lowest at the concentration of $10^{4}$ at the metabolic time of $240 \mathrm{~min}$.

At the concentration of $10^{6}$ cells $/ \mathrm{ml}$, HOK showed a metabolic time-dependent increase in the fluorescence intensity in the 5-ALA (+) group, but not in the 5-ALA (-) group. Furthermore, there was a significant difference in the fluorescence intensity between the 5-ALA $(+)$ and 5-ALA $(-)$ groups after $100 \mathrm{~min}(P<$ 0.05).

The fluorescence intensity in the 5-ALA (+) group was increased by about 2.3-fold at $700 \mathrm{~min}$ when compared to that immediately after 5-ALA administration (Figure $4(\mathrm{a})$ ). 


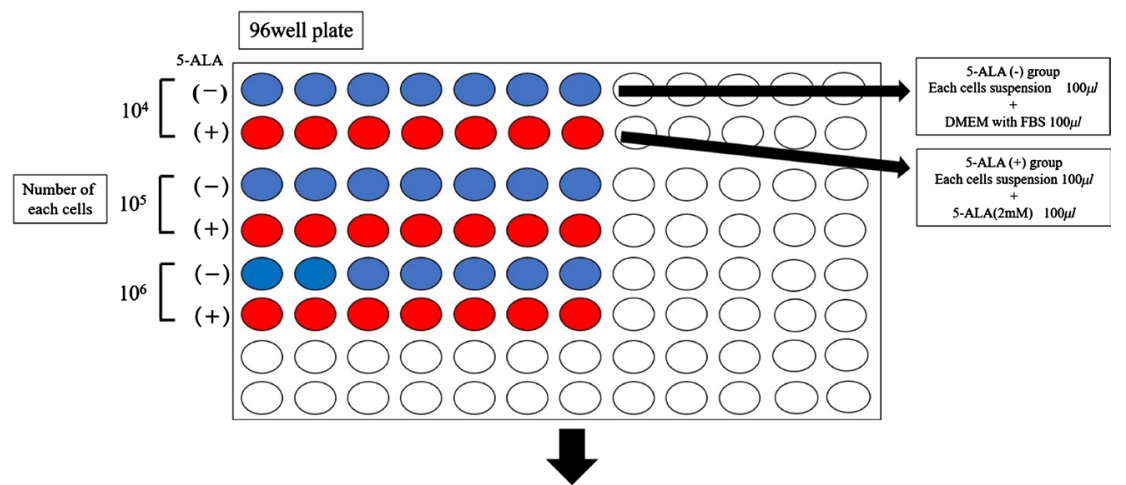

1420 Multilable/Luminescence Counter ARVO MX

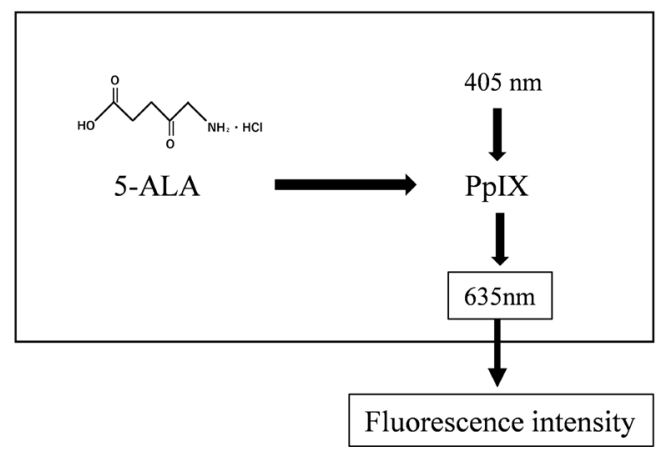

Figure 2. Measurement of the fluorescence intensity of each cell line using PDD. Each cell line was divided into two groups: A group treated with 5-ALA (5-ALA $(+))$ and a group without 5-ALA treatment as the control group (5-ALA (-)). For each cell line, $100 \mu$ lof each of the tested concentrations of cells $\left(10^{4}, 10^{5}\right.$, and $10^{6}$ cells $\left./ \mathrm{ml}\right)$ was added to 96 -well luminescence plates, and the fluorescence intensity was measured at 60 -min intervals for $240 \mathrm{~min}$. Subsequently, the fluorescence intensity of cells at $10^{6}$ cells/ml, which was the concentration that showed the strongest fluorescence intensity, was measured at 20-min intervals for $700 \mathrm{~min}$ under the same conditions $(\mathrm{n}=7)$. The fluorescence intensity was measured using a 1420 Multilabel/Luminescence Counter ARVO MX. Cells were irradiated with a wavelength of $405 \mathrm{~nm}$, which is the excitation wavelength of the PpIX produced from 5-ALA, and the emitted fluorescence at a wavelength of $635 \mathrm{~nm}$ was measured as the fluorescence intensity.

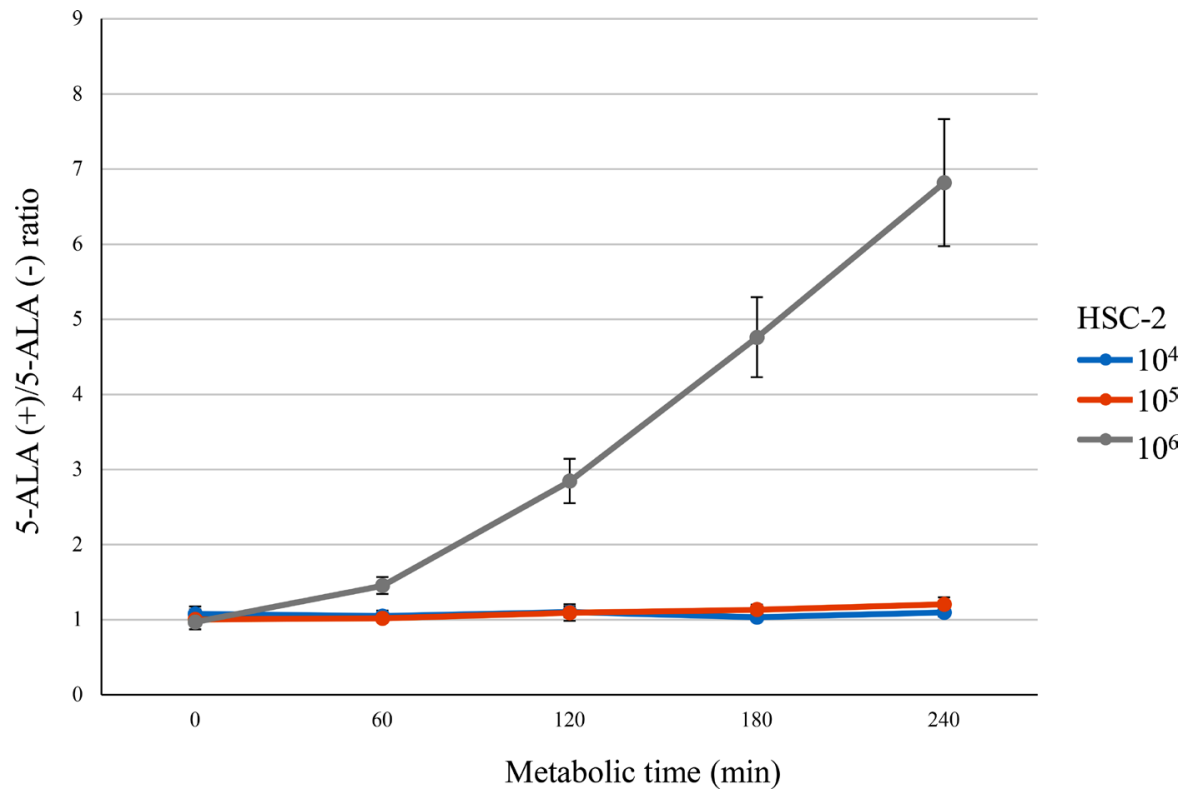

(a) 


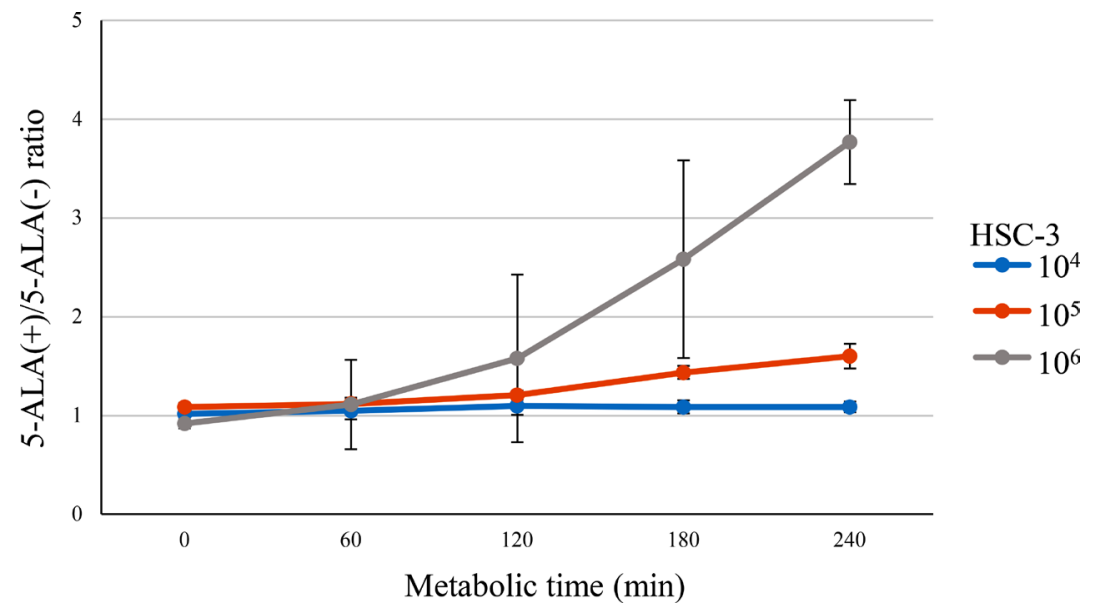

(b)

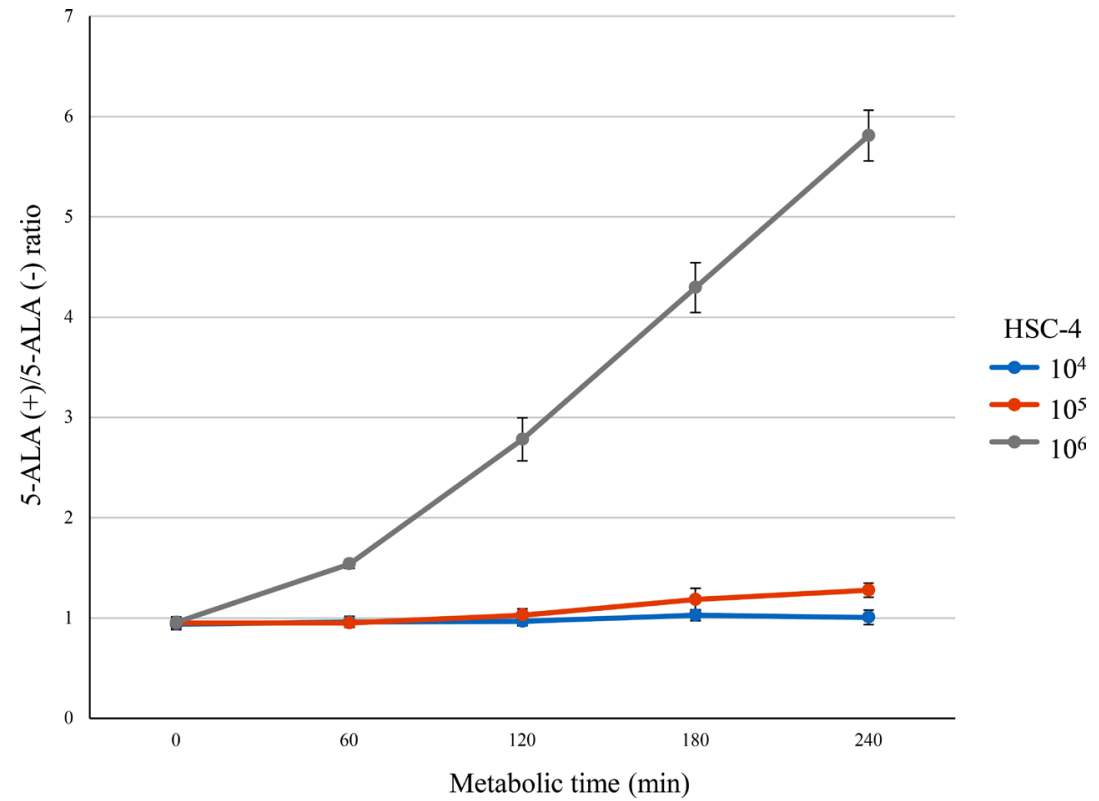

(c)

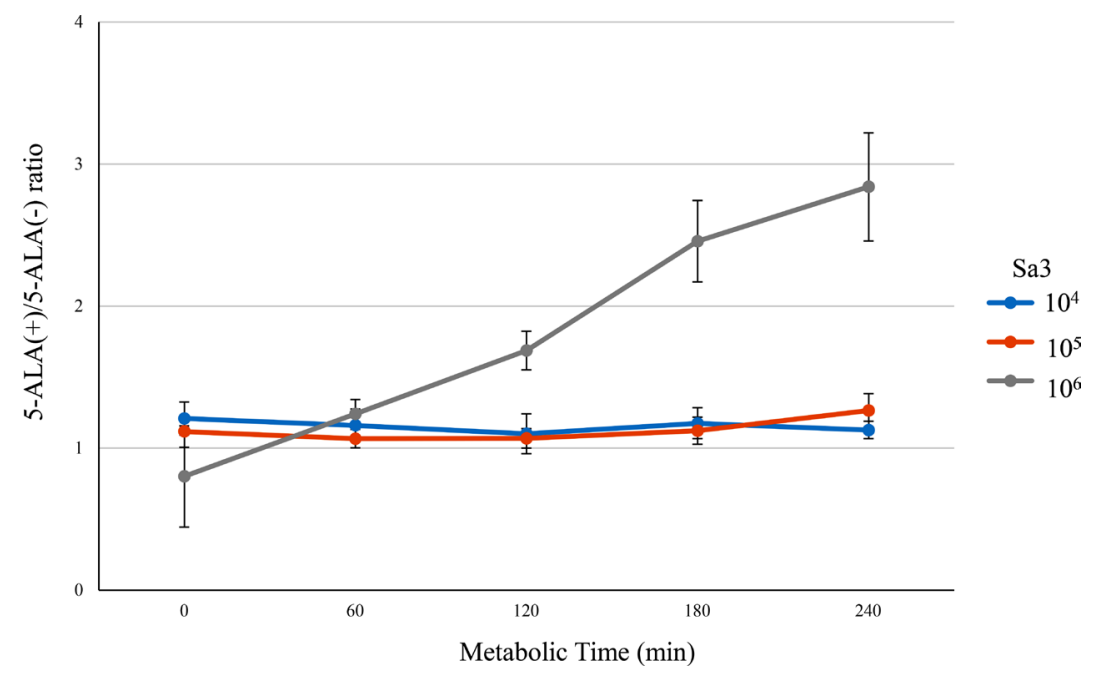

(d) 
Figure 3. The 5-ALA (+)/5-ALA (-) ratio of each cell line at different cell concentrations $\left(10^{4}, 10^{5}\right.$, and $10^{6}$ cells $\left./ \mathrm{ml}\right)$. The 5-ALA (+)/5-ALA (-) ratios of (a) HSC-2, (b) HSC-3, (c) HSC-4, and (d) Sa3 cells are shown. The y-axis shows the ratio of the fluorescence intensity of the 5-ALA (-) group to that of the 5-ALA (+) group. The $\mathrm{x}$-axis indicates the metabolic time. The blue, orange, and gray lines indicate $10^{4}, 10^{5}$, and $10^{6} \mathrm{cells} / \mathrm{ml}$, respectively. In all cell lines, the 5-ALA (+)/5-ALA (-) ratio increased in a cell concentration-dependent manner: It was highest at the concentration of $10^{6}$, and lowest at the concentration of $10^{4}$ at the metabolic time of $240 \mathrm{~min}$.

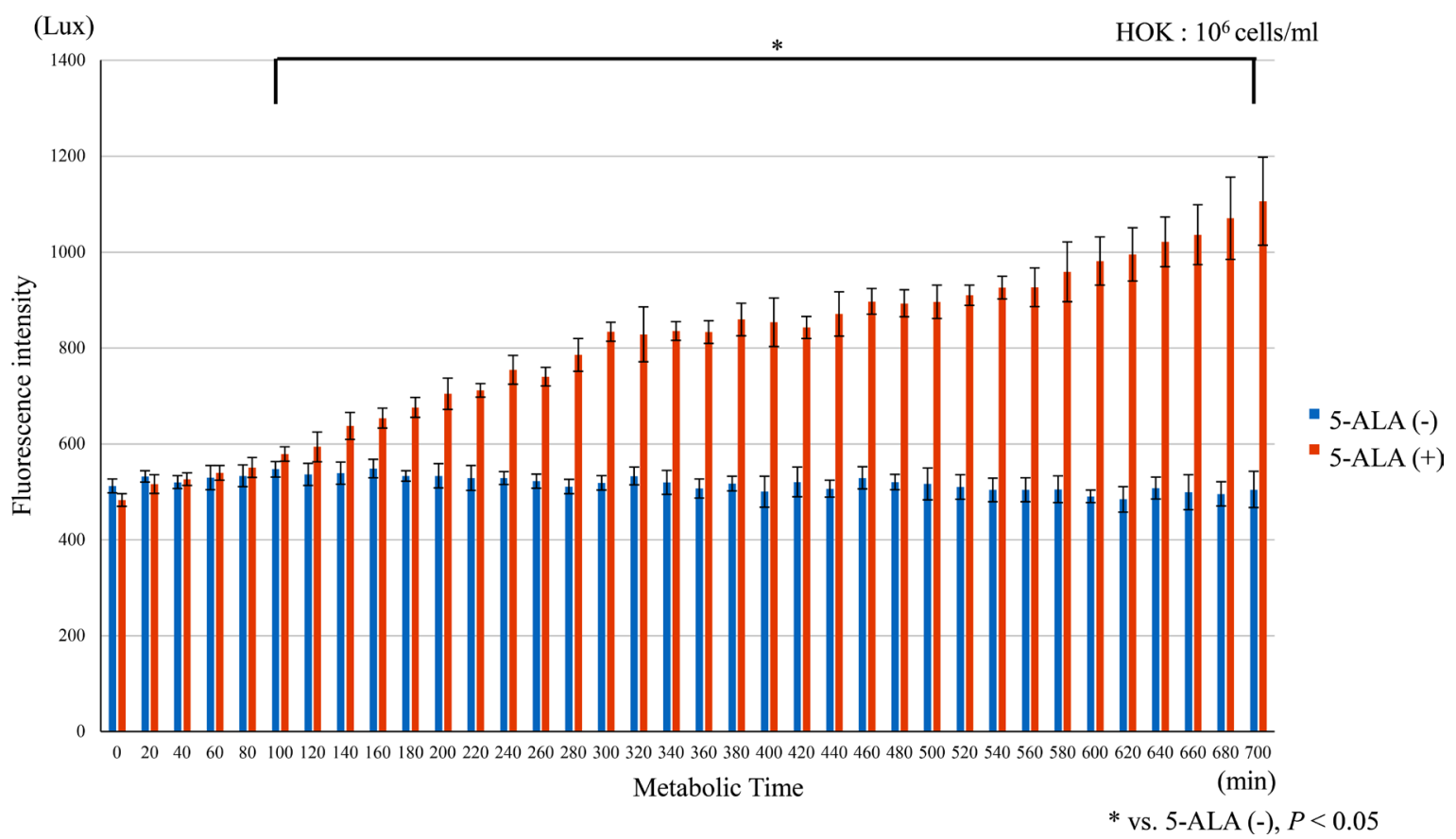

(a)

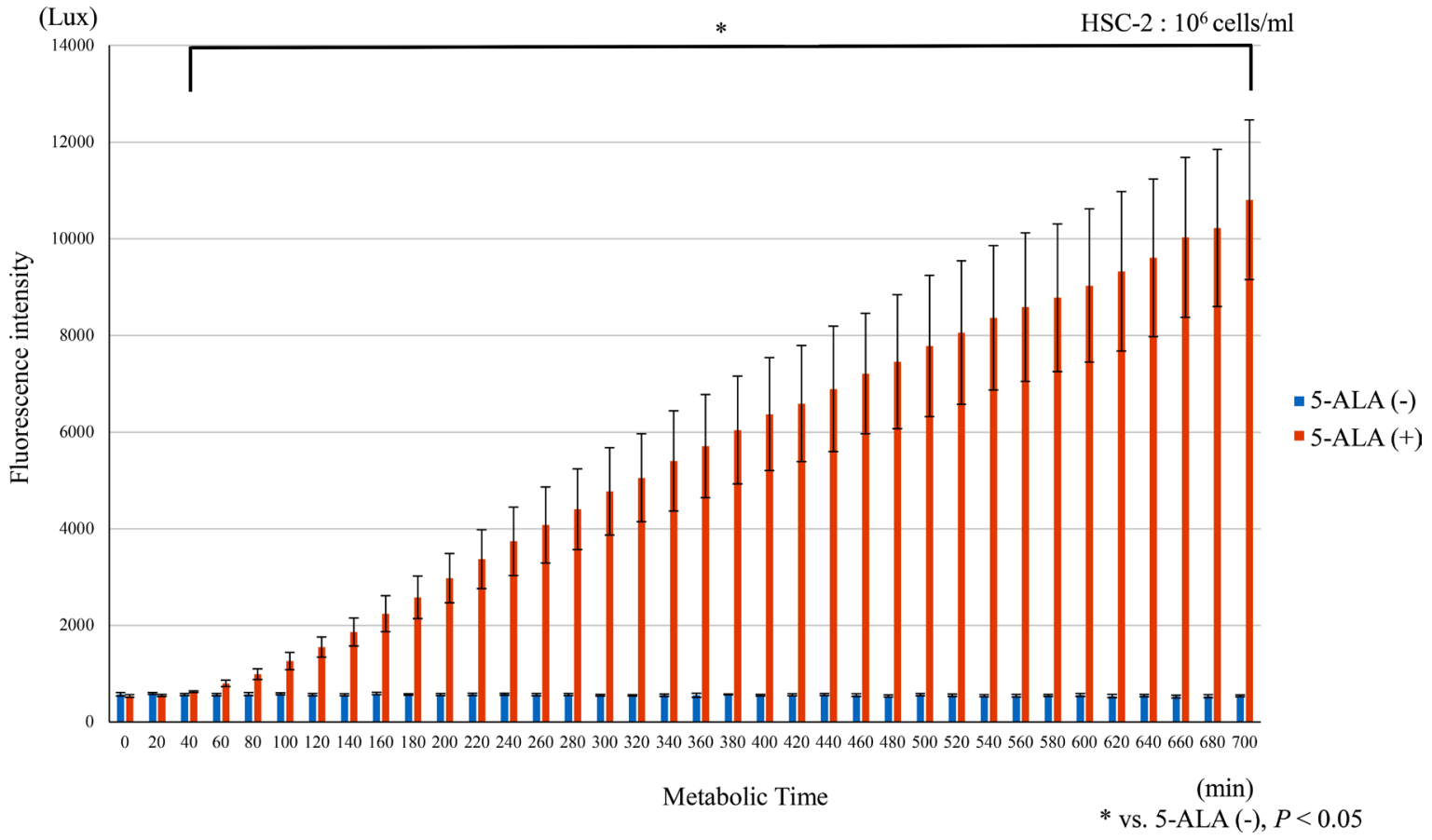

(b) 


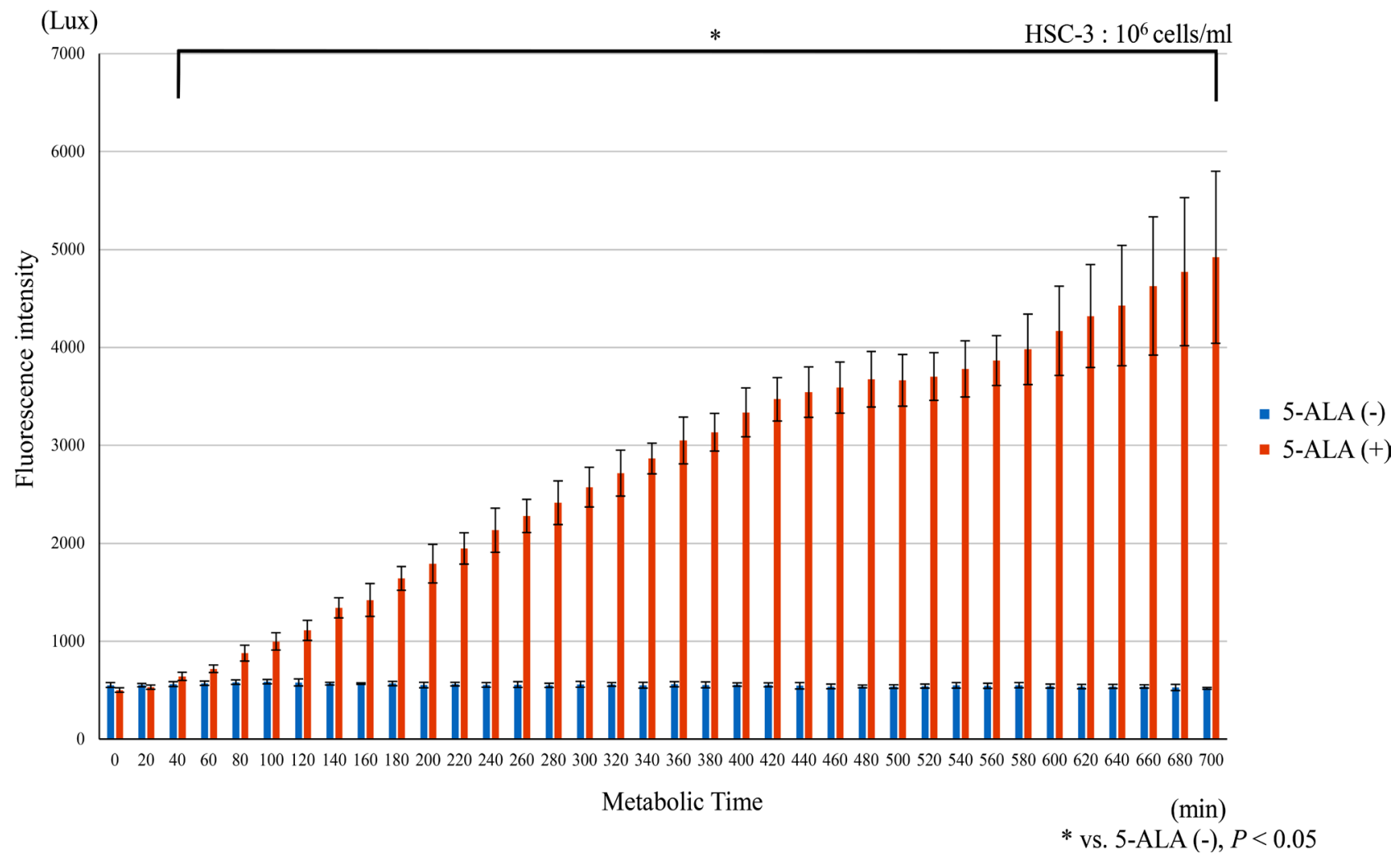

(c)

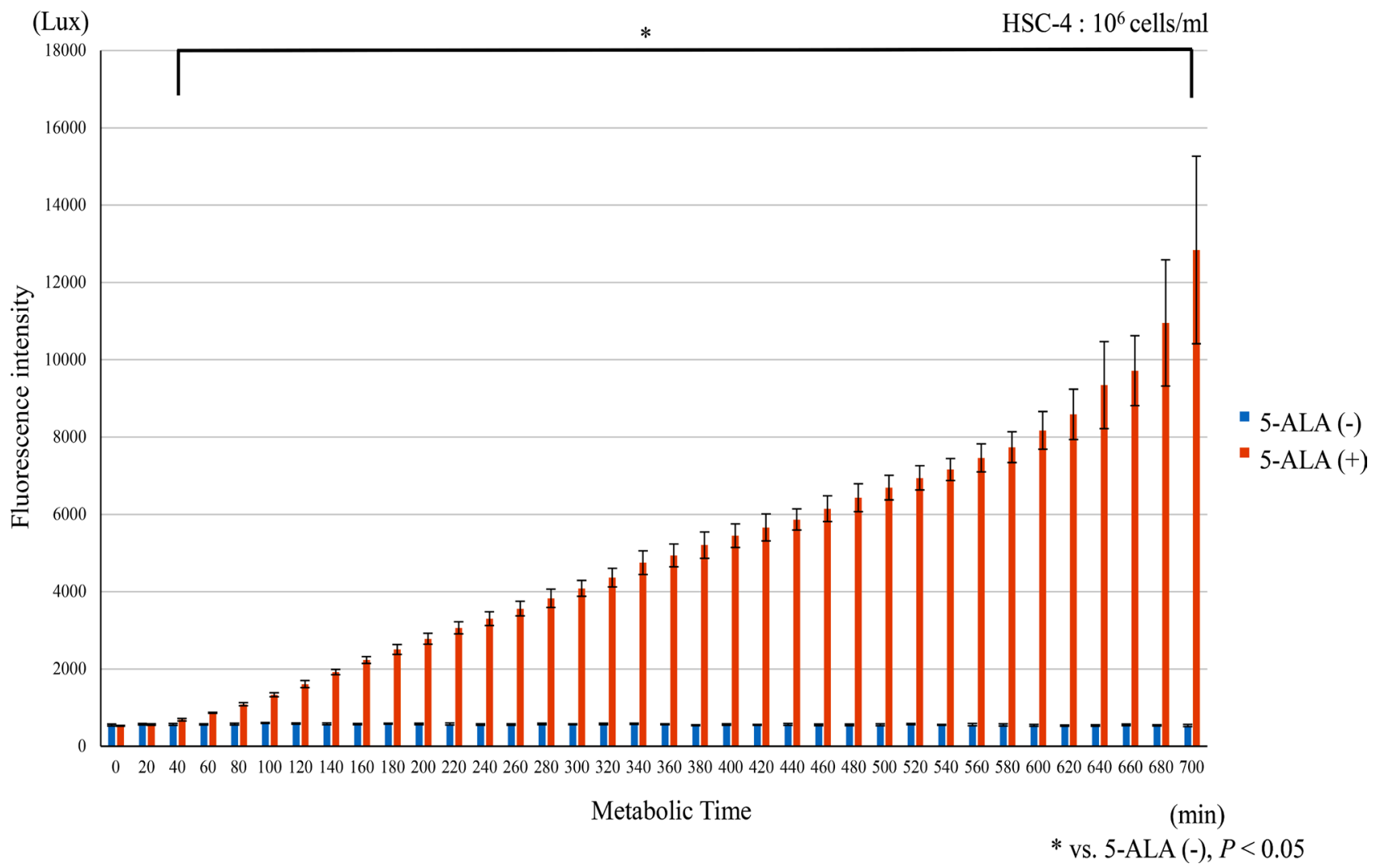

(d) 


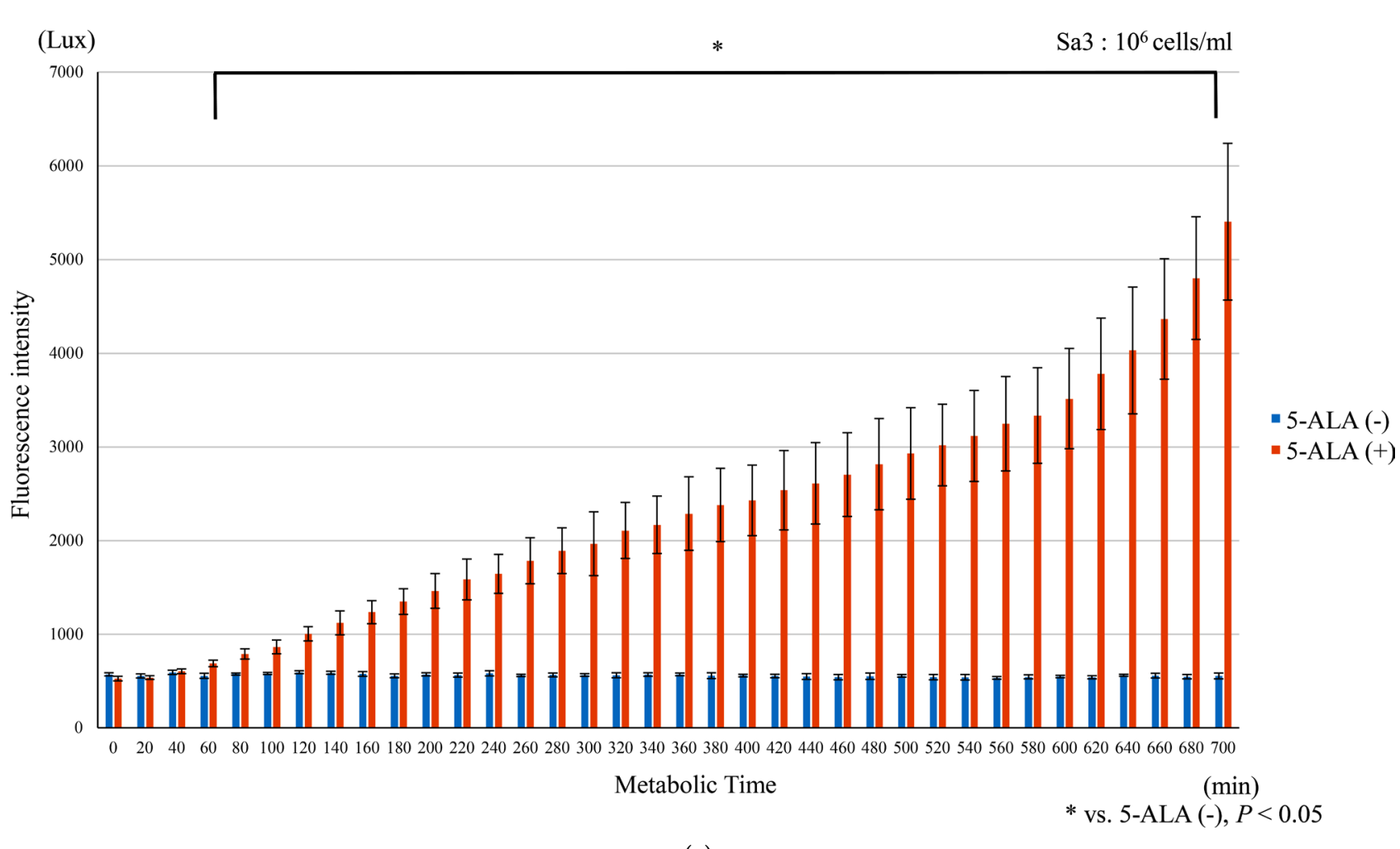

(e)

Figure 4. The fluorescence intensities of various types of cultured cells at $10^{6}$ cells $/ \mathrm{ml}$. The fluorescence intensities in (a) HOK, (b) HSC-2, (c) HSC-3, (d) HSC-4, and (e) Sa3 cells are shown. The y-axis shows the fluorescence intensity of each cell line that was irradiated with 405-nm light and emitted fluorescence at a wavelength of $635 \mathrm{~nm}$. The $\mathrm{x}$-axis shows the metabolic time of 5-ALA. The blue and orange bars indicate the fluorescence intensity of the 5-ALA (-) and 5-ALA (+) groups, respectively. The fluorescence intensity was increased in the 5-ALA (+) group when compared to the 5-ALA ( - ) group in all cultured cells. ( ${ }^{*}$ vs. 5-ALA $(-), P<0.05$ (mean $\pm \mathrm{SD}$ ). The columns indicate the values $(\mathrm{n}=7)$ with standard deviation bars.)

The fluorescence intensity of HSC-2, HSC-3, and HSC-4 cells showed metabolic time-dependent changes in the 5-ALA (+) group, but not in the 5-ALA (-) group. There was a significant difference in the fluorescence intensity between the 5-ALA $(+)$ and 5-ALA $(-)$ groups after $40 \mathrm{~min}(P<0.05)$. Furthermore, the fluorescence intensity of HSC-2, HSC-3, and HSC-4 cells in the 5-ALA (+) group was increased by about 20.4-, 9.8-, and 24.4-fold, respectively, at $700 \mathrm{~min}$ when compared to that immediately after 5-ALA administration (Figures 4(b)-(d)). Similarly, in Sa3 cells, the fluorescence intensity changed in a metabolic time-dependent manner in the 5-ALA (+) group, but not in the 5-ALA (-) group (Figure $4(\mathrm{e})$ ). There was a significant difference in the fluorescence intensity between the 5-ALA $(+)$ and 5-ALA $(-)$ groups after $60 \mathrm{~min}(P<0.05)$. In addition, the fluorescence intensity in the 5-ALA $(+)$ group was increased by about 10.2 -fold at $700 \mathrm{~min}$ when compared to that immediately after 5 -ALA administration.

In the 5-ALA (+) group, the increase in the fluorescence intensity was highest in HSC- 2 cells, followed by HSC- 4 cells, HSC-3 cells, Sa3 cells, and HOK. A significant difference was seen between the HOK and the HSC-2, HSC-3, HSC-4, and Sa3 cells after $40 \mathrm{~min}(P<0.05$; Figure 5$)$. 


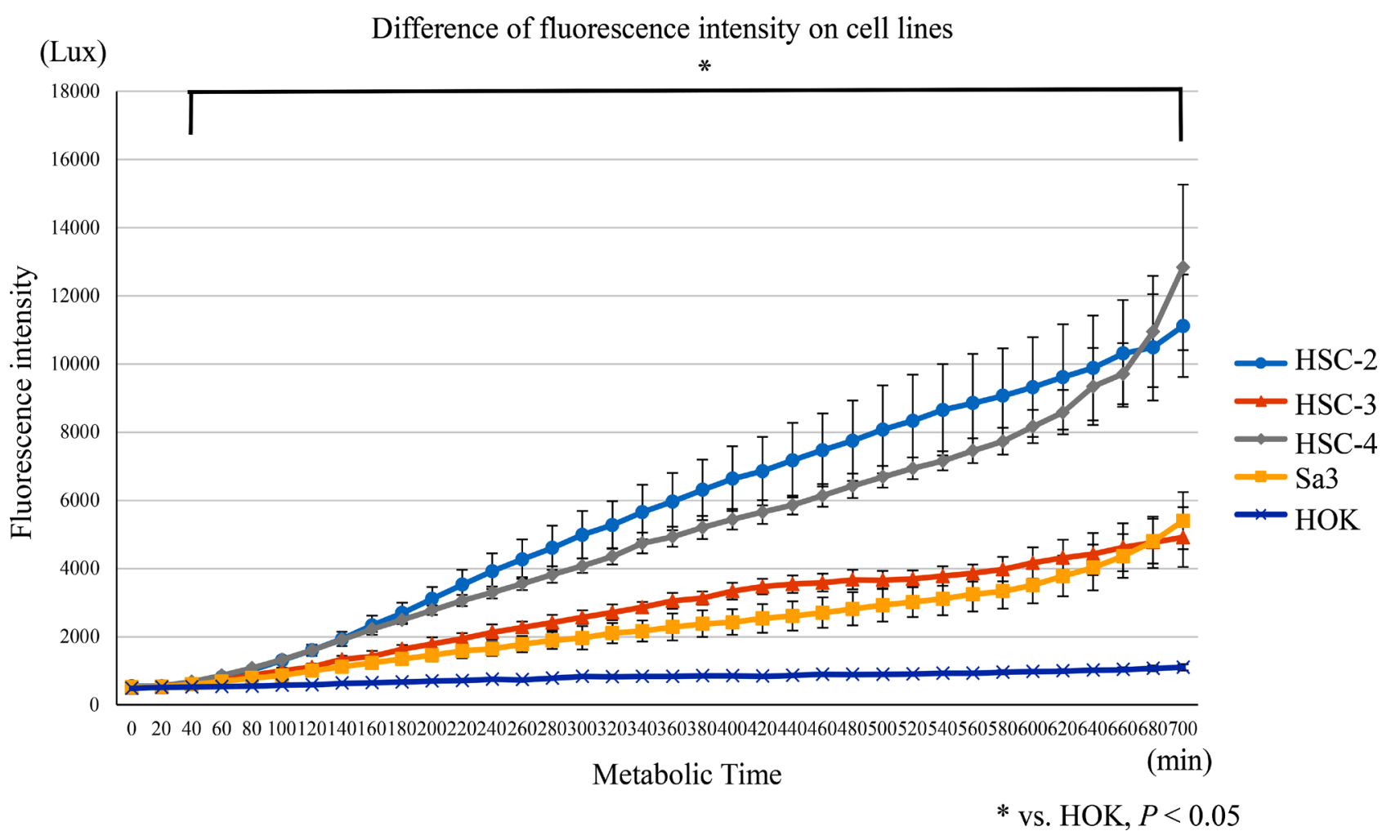

Figure 5. Differences in the fluorescence intensities of cell lines. The y-axis shows the fluorescence intensity of each cell line that was irradiated with $405-\mathrm{nm}$ light and emitted fluorescence at a wavelength of $635 \mathrm{~nm}$. The $\mathrm{x}$-axis shows the metabolic time of 5-ALA. The light blue, orange, gray, yellow, and blue lines indicate the fluorescence intensities of HSC-2, HSC-3, HSC-4, Sa3, and $\mathrm{HOK}$, respectively. In the 5-ALA (+) group at $10^{6} \mathrm{cells} / \mathrm{ml}$, the increase in the fluorescence intensity was highest in HSC-2, followed by HSC-4, HSC-3, Sa3, and HOK. A significant difference was seen between the HOK and the HSC-2, HSC-3, HSC-4, and Sa3 cells after $40 \mathrm{~min}\left({ }^{*} \mathrm{vs}\right.$. HOK, $P<0.05$ (mean $\left.\pm \mathrm{SD}\right)$. The data points indicate the values $(\mathrm{n}=7)$ with standard deviation bars.

\section{Discussion}

Recently, the use of 5-ALA to fluorescently label tumors has attracted much attention [12]. PpIX, a metabolite of 5-ALA, is thought to play a major role in enhancing the fluorescence intensity of tumor cells. The maximum excitation wavelength of PpIX is around $405 \mathrm{~nm}$ (blue light), and it fluoresces red light at around $630 \mathrm{~nm}$ when excited by excitation light [7] [8] [9] [10]. 5-ALA is a type of amino acid that is found in living organisms. It is a raw material for porphyrins, such as heme, vitamin B12, and chlorophyll, but it is not light-sensitive by itself. After passing through various metabolic pathways in the cytoplasm, 5-ALA becomes PpIX in the mitochondria, and divalent iron ions chelate with PpIX to form heme by the action of ferrochelatase [13]. The expression of ferrochelatase is regulated by the amount of iron in the cytoplasm, and the heme keeps the heme concentration constant via negative feedback [14]. However, in tumor cells, the synthesis of heme from PpIX is insufficient due to decreased activity of ferrochelatase [7]. Therefore, PpIX accumulates in tumor cells, and is observed as strong fluorescence under excitation wavelengths. In addition, the enzymatic activity required for the biosynthesis of PpIX is higher in malignant tumor cells than in normal cells, which may also contribute to the enhanced fluorescence 
intensity of tumor cells.

From the results of this study, we estimated that a concentration of at least $10^{6}$ cells/ml is necessary for evaluation using PDD with a luminescence plate reader, because a remarkable fluorescence intensity is needed for improved diagnostic accuracy.

We measured the changes in the fluorescence intensity obtained by incorporating 5-ALA into various cultured OSCC cell lines and $\mathrm{HOK}$ at $10^{6}$ cells $/ \mathrm{ml}$ and irradiating them with excitation light. Although there were some differences between the OSCC cell lines, a significant increase in fluorescence intensity was observed from 40 to $60 \mathrm{~min}$ after the administration of 5-ALA. Although an increase in fluorescence intensity was also observed in $\mathrm{HOK}$, it took longer to detect a significant difference, and the difference was smaller than those of the various cultured OSCC cell lines. These differences may be attributable to the fact that there was no decrease in ferrochelatase activity in the HOK, meaning that metabolism was normal and a certain amount of PpIX was produced. This would explain why the fluorescence intensity increased with the passage of time, albeit only weakly.

The differences in the increase in fluorescence intensity among the cultured OSCC cell lines were considered to be due to the differences in the primary sites, the sites of collection, and the degree of tumor differentiation. Regarding the differentiation levels of the tumors in this study, HSC-2, HSC-4, and Sa3 cells were highly differentiated cell lines [15] [16] [17] [18], while HSC-3 was a poorly differentiated cell line, suggesting that the fluorescence intensity is higher in highly differentiated cells (Table 1). However, some other studies have reported that the fluorescence intensity was enhanced in poorly differentiated cells [19], which is in contrast with the results of this study. To clarify this point, we believe that further investigations using larger numbers of cell lines are necessary.

Furthermore, in this study, the concentration of cultured cells required to observe a significant difference in fluorescence intensity was $10^{6}$ cells $/ \mathrm{ml}$. However, we estimate that the number of cells that can be clinically harvested from a lesion with a cytobrush is less than $10^{6}$ cells $/ \mathrm{ml}$. Related to this, some studies have reported that the combination of 5-ALA with deferoxamine increased the

Table 1. Primary site, site of collection, and differentiation level of various human oral squamous cell carcinoma-derived cell lines. (Taken from the literature with some modifications [15]).

\begin{tabular}{|c|c|c|c|c|}
\hline Name & $\mathrm{Sa} 3$ & HSC-2 & HSC-3 & HSC-4 \\
\hline Primary lesion & maxillary gingiva & mouth, bottom & tongue & tongue \\
\hline Site of collection & & $\begin{array}{l}\text { submandibular } \\
\text { lymph node } \\
\text { metastases }\end{array}$ & $\begin{array}{l}\text { metastasis in the } \\
\text { middle and deep } \\
\text { cervical lymph } \\
\text { nodes }\end{array}$ & $\begin{array}{l}\text { metastasis in the } \\
\text { middle and deep } \\
\text { cervical lymph } \\
\text { nodes }\end{array}$ \\
\hline $\begin{array}{c}\text { Degree of } \\
\text { differentiation }\end{array}$ & high & high & low & high \\
\hline
\end{tabular}


accumulation of PpIX. Deferoxamine, which is an iron-chelating agent, inhibits the synthesis of PpIX into heme, promotes intracellular PpIX accumulation, and enhances the fluorescence intensity [19] [20] [21] [22]. Furthermore, Kitajima et al. reported that the accumulation of PpIX was enhanced by culturing cells with the dynamin inhibitor myristyl trimethyl ammonium bromide and fumitremorgin $C$ in combination with 5-ALA (Figure 6) [23]. By applying these three factors, we expect that the amount of PpIX accumulation would increase in tumor cells, and that it would be possible to observe the increases in the fluorescence intensity in a smaller amount of cells.

The method of a conventional 5-ALA-PDD diagnosis is performed intraoperative or fluorescence microscopy, and its accuracy depends on the professional experience of the surgeon. The novelty of our newly developed method is that the fluorescence intensity can be quantified and evaluated by a luminescence plate reader, which may be useful for general clinicians in the future. Table 2 lists the advantages and disadvantages of PDD using a luminescent plate reader in comparison to conventional PDD. Furthermore, if normal cells and tumor

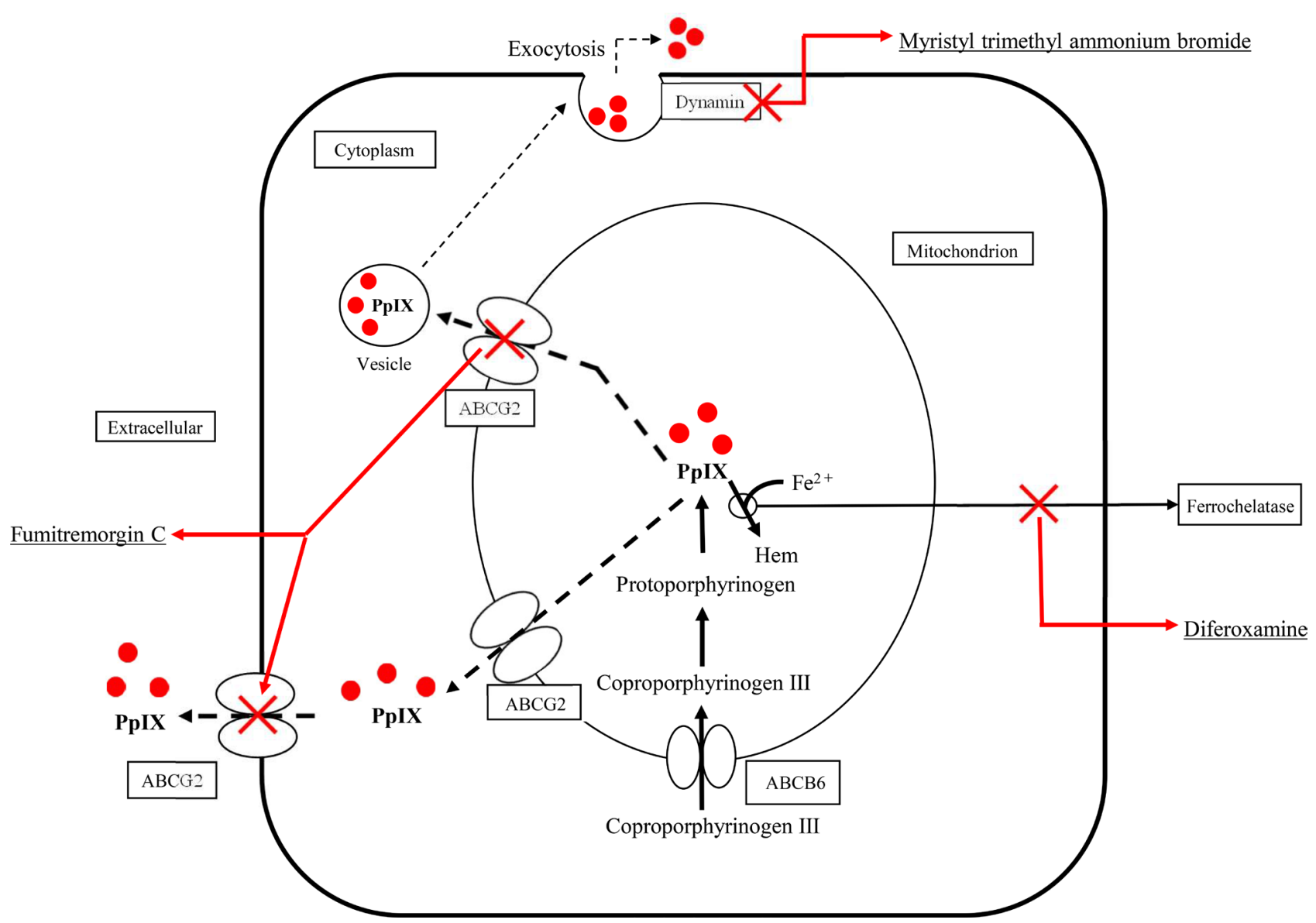

Figure 6. Action points of PpIX-excretion inhibitors. (Taken from the literature with some modifications [9] [19] [20] [21] [22] [23]). Schematic representation of the mechanism by which PpIX accumulation in cells is promoted by PpIX-excretion inhibitors. Deferoxamine, which is an iron-chelating agent, inhibits the synthesis of PpIX into heme, and promotes intracellular PpIX accumulation. Furthermore, the accumulation of PpIX is enhanced when cells are cultured with the dynamin inhibitors myristyl trimethyl ammonium bromide and fumitremorgin $\mathrm{C}$ in combination with 5-ALA. 
Table 2. The advantages and disadvantages of PDD using a luminescent plate reader in comparison to conventional PDD.

\begin{tabular}{clc}
\hline & \multicolumn{1}{c}{ Advantages } & Disadvantages \\
\hline Conventional PDD & Requires a small number of cells. & $\begin{array}{c}\text { Requires } \\
\text { professional } \\
\text { experience. }\end{array}$ \\
& Intraoperative diagnosis is possible. & \\
$\begin{array}{c}\text { PDD using a } \\
\text { luminescence plate } \\
\text { reader }\end{array}$ & $\begin{array}{l}\text { Can be evaluated by general clinicians since } \\
\text { the fluorescence intensity is quantified. }\end{array}$ & $\begin{array}{l}\text { Requires at least } \\
10^{6} \text { cells } / \mathrm{ml} .\end{array}$ \\
& $\begin{array}{l}\text { Can be applied to mass screening systems for } \\
\text { oral cancer. }\end{array}$ & \\
\hline
\end{tabular}

cells can be distinguished clearly by the fluorescence intensity values, this method may be applicable to mass screening systems for oral cancer. It will be necessary to investigate cells scraped directly from patients in a future study.

In conclusion, the results of this study suggest that PDD using 5-ALA for exfoliative cytology in clinical dental practice may be applied safely for accurately diagnosing oral cancer.

\section{Acknowledgments}

The authors would like to thank Professor M. Fukumoto from Nihon University School of Dentistry at Matsudo, helpful discussions and comments on the manuscript. This work was supported by JSPS KAKENHI Grant Number 20K10256.

\section{Conflicts of Interest}

The authors declare no conflicts of interest regarding the publication of this paper.

\section{References}

[1] Ministry of Health, Labour and Welfare (2020) 2019 Summary of Vital Statistics. Ministry of Health, Labour and Welfare.

https://www.mhlw.go.jp/toukei/saikin/hw/jinkou/kakutei19/index.html

[2] Nobuharu, Y., Kazumichi, S., Tomohiro, Y., Taiki, S., Ryuta, O., Mira, K., Yoshifumi, Y., Sunaki, N., Ken, I., Masayuki, T., Akira, K., Yoichi, T., Takahiko, S. and Nobuo, T. (2013) A 5-Year Activity Report from the Oral Cancer Center, Tokyo Dental College. The Bulletin of Tokyo Dental College, 54, 265-273. https://doi.org/10.2209/tdcpublication.54.265

[3] Takuro, K., Mika, S., Kanae, A., Noriko, O., Yasuyuki, M., Sakae, H. and Mitsuyoshi, H. (1997) Examination of Oversights in Screening. The Journal of the Japanese Society of Clinical Cytology, 36, 136-140. https://doi.org/10.5795/jjscc.36.136

[4] Masami, S., Mitsutoshi, S., Yasuki, S., Yukitoshi, S., Kiyoshi, S., Takaaki, T., Tomio, N., Takeshi, H., Norihiko, I., Ei, K., Hiroyuki, M., Ryutaro, N., Akemi, T., Kazunobu, Y., Nikako, S., Junko, K., Midori, N., Shinji, M., Yukihiro, S., Ryota, T. and Chiaki, E. (2015) Inter-Rater Agreement of Sputum Cytology for Lung Cancer Screening in Japan. The Japan Lung Cancer Society, 55, 859-865.

https://doi.org/10.2482/haigan.55.859 
[5] Akira, F., Kayo, K., Mana, F. and Masahiko, F. (2015) Comparison of Liquid-Based Cytology and Conventional Cytology in Squamous Cell Carcinoma. Journal of the Japan Academy of Oral Human Dock, 10, 41-48.

[6] Keiji, I., Hideo, F. and Taro, S. (2015) TURBT Assisted by Photodynamic Diagnosis Using Aminolevulinic Acid. Japanese Journal of Endourology, 28, 187-191.

[7] Masafumi, O. (2014) Photodynamic Diagnosis Using 5-Aminolevulinic Acid: A Clinical Approach to Urologic Tumors. Journal of Saitama Medical University, 41, 7-13.

[8] Hajime, I., Kumi, O., Takemasa, S., Ken, O., Naoyuki, Y., Kazuhiko, N. and Atsushi, N. (2015) 5-Aminolevulinic Acid Mediated Photodynamic Diagnosis with a Laser-Equipped Video Image Endoscope. The Japanese Language Society of Malaysia, 36, 113-118. https://doi.org/10.2530/jslsm.jslsm-36_0016

[9] Yoshinori, H. (2013) Fluorescence Diagnosis of Lymph Node Metastasis of Gastrointestinal Cancers by Using 5-Aminolevulinic Acid (5-ALA). Journal of Kyoto Prefectural University of Medicine, 122, 181-188.

[10] Jiro, A. (2016) Photodynamic Therapy for Malignant Brain Tumors. Neurologia Medico-Chirurgica, 56, 151-157. https://doi.org/10.2176/nmc.ra.2015-0296

[11] Masanao, Y., Hirohumi, F., Naoki, K., Keiji, I., Hitoshi, N., Kozo, U., Junzo, S. and Hideyo, O. (2013) Improvement of the Efficacy of 5-Aminolevulinic Acid-Mediated Photodynamic Treatment in Human Oral Squamous Cell Carcinoma HSC-4. Acta Medica (Okayama), 67, 153-164.

[12] Masaru, U., Ken, O., Yusuke, N., Shogo, H., Hiroyuki, H., Keiichi, M. and Hitoshi, T. (2010) Uptake and Kinetics of 5-Aminolevulinic Acid in Oral Squamous Cell Carcinoma. International Journal of Oral and Maxillofacial Surgery, 39, 802-805. https://doi.org/10.1016/j.ijom.2009.11.024

[13] Qian, P., Trond, W., Kristian, B., Johan, M., Magne, K., Karl-Erik, G. and Jahn, M.N. (1997) 5-Aminolevulinic Acid-Based Photodynamic Therapy: Clinical Research and Future Challenges. Cancer, 15, 2282-2308.

https://doi.org/10.1002/(SICI)1097-0142(19970615)79:12<2282::AID-CNCR2>3.0.C $\mathrm{O} ; 2-\mathrm{O}$

[14] Shigeru, T., Yasushi, A. and Yoshitsugu, N. (2000) Regulation of the Expression of Human Ferrochelatase by Intracellular Iron Levels. The FEBS Journal, 267, 4685-4692. https://doi.org/10.1046/j.1432-1327.2000.01519.x

[15] Fumio, M., Shouji, H., Toshio, A., Nobuyuki, T. and Shigetoshi, S. (1986) Characterization of Three Oral Squamous Cell Carcinoma-Derived Cells. Journal of the Japanese Stomatological Society, 35, 485-496.

[16] Masakazu, H., Kazuyuki, M., Takeshi, W., Tetsuji, O., Nobuo, M. and Tadayuki, S. (1993) Establishment and Characterization of a cell Line (Sa3) from Squamous Cell Carcinoma of the Human Gingiva. Journal of the Japanese Stomatological Society, 39, 965-971.

[17] Tomoyuki, H., Youhei, M., Fumihiro, H., Kanchu, T. and Motoaki, Y. (2020) ELAVL2 Expression in Oral Squamous-Cell Carcinoma cell Lines. Hokkaido Journal of Dental Science, 40, 79-86.

[18] Kazumasa, M., Yusuke, A., Hiroko, K., Tetsuya, T., Ryo, K. and Michio, A. (2018) TRKB Tyrosine Kinase Receptor Is a Potential Therapeutic Target for Poorly Differentiated Oral Squamous Cell Carcinoma. Oncotarget, 9, 25225-25243. https://doi.org/10.18632/oncotarget.25396

[19] Masaru, U. (2009) Fluorescence Analysis of Oral Squamous Cell Carcinoma with 5-Aminolevulinic Acid Labeling. The Journal of the Stomatological Society, Japan, 
76, 31-36.

[20] Petras, J., Asta, J. and Johan, M. (2005) Deferoxamine Photosensitizes Cancer Cells in Vitro. Biochemical and Biophysical Research Communications, 332, 388-391. https://doi.org/10.1016/j.bbrc.2005.04.138

[21] Pablo, A.V., Kimberley, S., O’Hara, J.A., Roberts, D.W., Paulsen, K.D. and Pogue, B.W. (2010) Deferoxamine Iron Chelation Increases $\delta$-Aminolevulinic Acid Induced Protoporphyrin IX in Xenograft Glioma Model. Journal of Photochemistry and Photobiology, 86, 471-475. https://doi.org/10.1111/j.1751-1097.2009.00664.x

[22] Yang, J.B., Xia, Y.M., Liu, X.M., Jiang, S. and Xiong, L.Y. (2010) Desferrioxamine Shows Different Potentials for Enhancing 5-Aminolevulinic Acid-Based Photodynamic Therapy in Several Cutaneous Cell Lines. Lasers in Medical Science, 25, 251-257. https://doi.org/10.1007/s10103-009-0721-0

[23] Kitajima, Y., Ishii, T., Kohda, T., Ishizuka, M., Yamazaki, K., Nishimura, Y., Tanaka, T., Dan, S. and Nakajima, M. (2019) Mechanistic Study of PpIX Accumulation Using the JFCR39 Cell Panel Revealed a Role for Dynamin 2-Mediated Exocytosis. Scientific Reports, 9, Article No. 8666. https://doi.org/10.1038/s41598-019-44981-y 